\title{
Photocontrol of the Structure and Functions of a Polypeptide Membrane Composed of Poly(L-glutamic acid) Containing Pararosaniline Leucocyanide Groups in the Side Chains
}

\author{
Morimasa SATo, Takatoshi KinOSHITA, * Akira TAKizAwa, \\ and Yoshiharu TsuJITA \\ Department of Materials Science \& Engineering, Nagoya Institute of Technology, \\ Gokiso-cho, Showa-ku, Nagoya 466, Japan
}

(Received October 5, 1988)

\begin{abstract}
A photo-responsive polypeptide membrane composed of poly(L-glutamic acid) (PGA) containing $38.3 \mathrm{~mol} \%$ pararosaniline leucocyanide (rose $(\mathrm{CN})$ ) groups in the side chains was prepared. The ultraviolet (UV) light irradiation could produce cationic side chains along the polypeptide backbone resulting from a photodissociation of rose $(\mathrm{CN})$ side chains in the membrane, which arises an electrostatic repulsive forces among the cationic side chains. This increased electrostatic repulsive force destabilized the $\alpha$-helical structure of the rose(CN)-PGA in the membrane. As a result, the membrane functions of rose $(\mathrm{CN})-\mathrm{PGA}$, such as membrane potential and transport properties, were strongly dependent on UV light irradiation, especially, the permeability of $\mathrm{KCl}$ through the rose(CN)-PGA membrane was much increased by a factor of 16 upon UV irradiation. The photoinduced changes of the membrane functions were reversible and consistent with the photoinduced conformational changes of rose(CN)-PGA membrane.

KEY WORDS Photoresponsive Polypeptide / Membrane / Pararosaniline Leucocyanide Side Chain / Photoinduced Conformational Change / Photoinduced Membrane Potential Change / Photoinduced Permeability Change /
\end{abstract}

Photo-responsive polymeric materials are primary concerns in the development of information technology. Many studies of photoinduced effects on polymers have been published, such as photochromism in polymer matrices, ${ }^{1}$ photoinduced transitions of polymer conformation, ${ }^{2-4}$ photo-viscosity effect $^{5-7}$ and so on. However, there are few studies on photoinduced changes of functions of polymer membranes containing photochromic groups incorporated as pendant groups in the polymer chains.

In previous studies, we showed that the transport properties of polypeptide membranes are strongly dependent upon the back-

\footnotetext{
* To whom correspondence should be addressed.
}

bone conformation of the polypeptides, e.g., $\mathrm{pH}$-induced conformational change of poly( $\mathrm{L}$ glutamic acid), ${ }^{8}$ redox-controlled conformational changes of poly(L-cystein). ${ }^{9}$ Recently, we also reported the photo-induced conformational changes of poly(L-glutamic acid) containing azobenzenesulfonate ${ }^{10}$ and pararosaniline leucohydroxide moieties, ${ }^{11}$ respectively, in the side chains. The conformation of the membrane composed of poly(L-glutamic acid) containing pararosaniline leucohydroxide moieties in the side chains was changed by a $\mathrm{pH}$ increase resulting from the photoproduction of $\mathrm{OH}^{-}$ions from the leucohydroxide moieties in the membrane phase. 


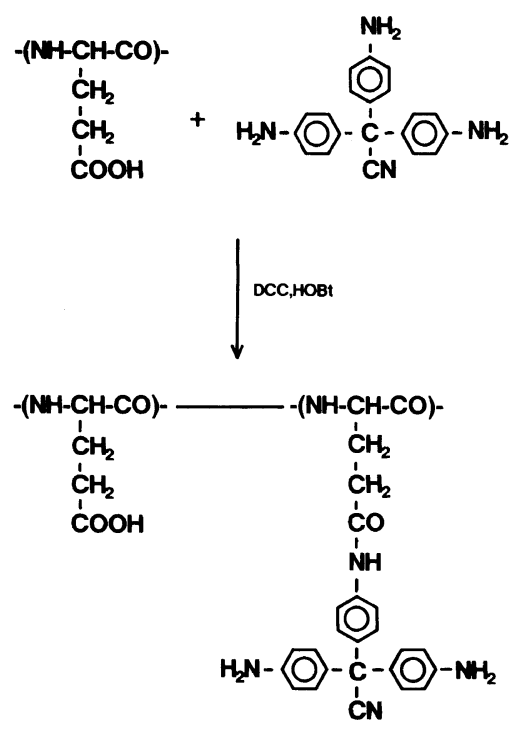

Scheme 1.

We report here the photo-control of the conformation and functions of a polypeptide membrane composed of poly(L-glutamic acid) containing triarylmethane leucocyanide groups in the side chains based on the photodissociation of the photochromic moieties. In this case, the $\mathrm{pH}$ in the membrane phase could not be changed by UV irradiation, because the triarylmethane leucocyanide moieties were dissociated into triarylmethyl cations and $\mathrm{CN}^{-}$ions by the irradiation. Consequently, we examined the effects of the photo-produced cationic side chains on the structure and functions of the polypeptide membrane.

\section{EXPERIMENTAL}

\section{Materials}

Pararosaniline leucocyanide $(\operatorname{rose}(\mathrm{CN}))$ was prepared by the method of Calvert et al. ${ }^{12}$ A saturated aqueous solution containing potassium cyanide was added to an aqueous solution containing pararosaniline hydrochroride (rose $\cdot \mathrm{HCl}$ ) at $25^{\circ} \mathrm{C}$. Then the precipitated pararosaniline leucocyanide (rose $(\mathrm{CN})$ ) was collected and washed with distilled water. $\operatorname{Rose}(\mathrm{CN})$ obtained was recrystallized with acetone/water for several times.
Poly(L-glutamic acid) (PGA, $M_{v}=1.19 \times$ $\left.10^{5}\right)$ was obtained by saponifying $\operatorname{poly}(\gamma-$ methyl L-glutamate) (PMLG) as previously reported. $^{13}$

Poly(L-glutamic acid) incorporated $\operatorname{rose}(\mathrm{CN})$ groups was synthesized as follows. PGA was dissolved in dimethylformamide (DMF) at $0^{\circ}$ C. Rose $(\mathrm{CN})$, dicyclohexylcarbodiimide (DCC) and $N$-hydrobenzotriazole ( $\mathrm{HOBt}$ ) were added to the stirred DMF solution at $0^{\circ} \mathrm{C}$. After $1 \mathrm{~h}$, the mixture was further stirred for $48 \mathrm{~h}$ at $25^{\circ} \mathrm{C}$. Precipitated dicyclohexylcarbodiurea (DCUrea) was filtered out and bulk of the DMF solution was poured into ethanol. Then the residue obtained was dissolved in DMF again and $\operatorname{rose}(\mathrm{CN})-$ PGA was precipitated with ethanol. This procedure was repeated until no unreacted low molecular weight reagents were detected spectroscopically.

The content of rose $(\mathrm{CN})$ groups in $\operatorname{rose}(\mathrm{CN})-$ PGA determined by an elemental analysis was $38.3 \mathrm{~mol}^{\circ}$.

The DMF solution $\left(2 \mathrm{wt}^{\mathrm{o}} \%\right.$ ) of $\operatorname{rose}(\mathrm{CN})-$ PGA was poured onto a quartz glass plate or into a petri dish and evaporated at $40^{\circ} \mathrm{C}$ for one day. The membrane obtained was then dried in vacuo.

\section{Measurements}

Absorption and circular dichroism (CD) measurements were carried out with a JASCO UVIDEC 670 spectropotometer and a JASCO J-40C spectropolarimeter, respectively. A qua$\mathrm{rtz}$ glass plate $(0.9 \mathrm{~cm} \times 5 \mathrm{~cm})$ coated with rose $(\mathrm{CN})-$ PGA membrane was inserted in a quartz cell filled with an aqueous solution (a distilled water of $\mathrm{pH}$ 5.3). The membrane was set in the cell lying perpendicular to the incident beam in the spectroscopic apparatus. The thickness of the water-swollen membrane on the plate was $1-5 \mu \mathrm{m}$. The molar ellipticity, $[\theta]$, was estimated by eq 1 .

$$
[\theta]=\frac{\theta \times M_{w}}{d \times l}
$$


where $\theta, M_{w}, d$ and $l$ are ellipticity, residual molecular weight, density and membrane thickness, respectively.

The cell circuit for the determination of membrane potentials, $\Delta(\Delta \phi)$, is represented by

$$
\begin{aligned}
\mathrm{Ag} \cdot \mathrm{AgCl} \mid \text { sat. } \mathrm{KCl} \mid & c_{1} \mid \text { membrane } \mid \\
c_{2} \mid & \text { sat. } \mathrm{KCl} \mid \mathrm{Ag} \cdot \mathrm{AgCl}
\end{aligned}
$$

where $\mathrm{Ag} \cdot \mathrm{AgCl}$ is electrode and junctions 1 and 2 were connected by salt bridges. In this case, $c_{1}$ and $c_{2}\left(c_{1}>c_{2}\right)$ are $\mathrm{KCl}$ concentrations and the potential of the lower $\mathrm{KCl}$ concentration $\left(c_{2}\right)$ side was taken as zero. The $\mathrm{KCl}$ concentration ratio, $c_{1} / c_{2}$, was fixed at 10 . Membrane potential measurements were performed at $25^{\circ} \mathrm{C}$.

Measurements of the permeation of $\mathrm{KCl}$ through a membrane were carried out using a permeation cell at $25^{\circ} \mathrm{C}$. A $1.0 \mathrm{~mol} \mathrm{dm}^{-3}$ aqueous solution of $\mathrm{KCl}$ was introduced into one side of the cell and a solute free solution was introduced into the other side (permeated side) of the cell. The degree of permeation through the membrane was determined by measurement of the conductance of the solution of the permeated side of the cell. The $\mathrm{KCl}$ concentration of the permeated side was calculated from the conductance-concentration relation of $\mathrm{KCl}$. The permeability coefficient, $P_{\mathrm{s}}$, of $\mathrm{KCl}$ through the membrane was determined by eq 2 .

$$
P_{\mathrm{s}}=-\frac{J_{\mathrm{s}} \times d}{\Delta c}
$$

where $J_{\mathrm{s}}, d$, and $\Delta c$ are the flux of $\mathrm{KCl}$ through the membrane, membrane thickness and the $\mathrm{KCl}$-concentration difference across the membrane.

The degree of hydration of the membrane, $H$, weight fraction of water in the waterswollen membrane, was determined at $25^{\circ} \mathrm{C}$. The membrane was allowed to swell in the dark and UV irradiation, respectively, blotted and weighed until constant weight was obtained, and then dried under reduced pressure.
$H$ was calculated from the difference of the weights.

For measurement of the degree of hydration, membrane potentials, and permeability, water-swollen membranes of $15-20 \mu \mathrm{m}$ in thickness were used.

Irradiation was carried out by a $500 \mathrm{~W}$ ultra-high-pressure mercury lamp (USHIO UVD-500) equipped with a Toshiba glass filter UVD-33S for ultra-violet light irradiation $(250 \mathrm{~nm}<\lambda<380 \mathrm{~nm})$.

For all measurements, the membranes were kept in the dark for a few days to ensure that all of $\operatorname{rose}(\mathrm{CN})$ groups would be in the leucocyanide form at the beginning of the measurements.

\section{RESULTS AND DISCUSSION}

Photoinduced Dissociation of Triarylmethane Leucocyanide Groups in Rose(CN)-PGA Membrane

Triarylmethane leucocyanide derivatives are well-known to dissociate into ion pairs under ultraviolet light irradiation with production of cyanide ions and colored triarylmethyl cations. The ion pairs dissociated thermally recombine again with each other in the dark. ${ }^{14}$

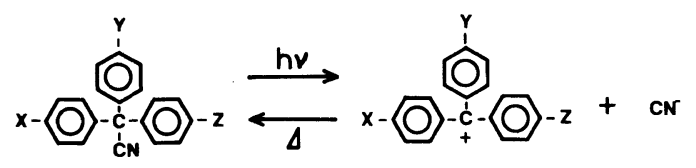

Figure 1 shows the UV-visible absorption spectra of the dark-adapted and irradiated rose $(\mathrm{CN})-\mathrm{PGA}$ membrane dipped in an aqueous solution at $\mathrm{pH}$ 5.3. It is clear that the light irradiation produced a strong absorption band centered at $576 \mathrm{~nm}$, which could be correlated with the formation of triarylmethyl cations. We have already shown ${ }^{15}$ that the pararosaniline leucohydroxide (rose $(\mathrm{OH}))$ moieties, whose $\mathrm{pKa}$ is 8.3 , in the polypeptide membrane composed of PGA containing rose groups in the side chains $(\operatorname{rose}(\mathrm{OH})-\mathrm{PGA})$ 


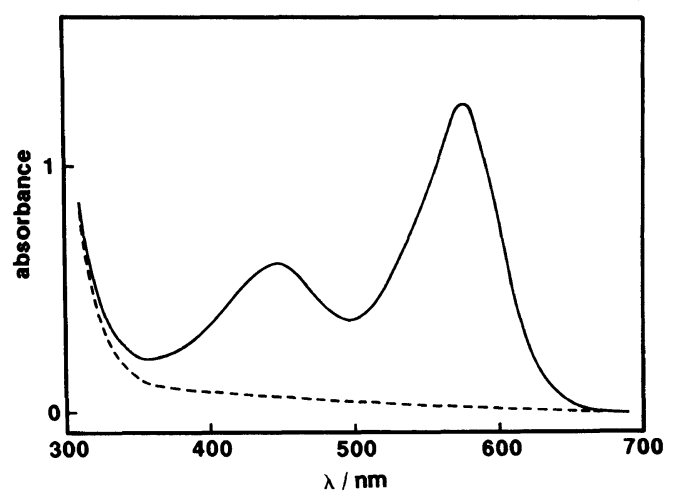

Figure 1. Absorption spectra of a membrane composed of rose $(\mathrm{CN})-\mathrm{PGA}$ at $25^{\circ} \mathrm{C}$ : ----, in the dark; - on UV irradiation.

could be dissociated in acid solution even in the dark due to the neutralization reaction. ${ }^{16}$ Their photodissociation could thus be achieved only in a limited $\mathrm{pH}$ region above neutrality. It was shown, however, that the pararosaniline leucocyanide $(\operatorname{rose}(\mathrm{CN}))$ moieties in the rose $(\mathrm{CN})-\mathrm{PGA}$ membrane did not dissociate in the wide range of $\mathrm{pH}$ in the dark. ${ }^{17}$ Consequently, the photoactivity of rose- $\mathrm{CN}$ moieties was, in fact, maintained in the acid solution (Figure 1). Therefore, the $\operatorname{rose}(\mathrm{CN})$ moieties in the $\operatorname{rose}(\mathrm{CN})-\mathrm{PGA}$ membrane could be dissociated by irradiation at $\mathrm{pH} 5.3$, yielding triarylmethyl cations in the side chains. It was also shown that, after removal of the light, the absorption band at $576 \mathrm{~nm}$ completely returned to the original value for $c a .15 \mathrm{~h}$ in the dark at $25^{\circ} \mathrm{C}$. Thus, it was confirmed that the light irradiation is able to reversibly produce positive charge on the rose $(\mathrm{CN})$ side chains along the polypeptide backbone, by the photodissociation of the photochromic moieties.

\section{Photoinduced Conformational Changes of} Rose $(C N)-P G A$ Membrane

Figure 2 shows the changes of the $C D$ spectra of the rose(CN)-PGA membrane dipped in aqueous solution on irradiation at $\mathrm{pH}$ 5.3. In the dark, a negative band at $222 \mathrm{~nm}$,

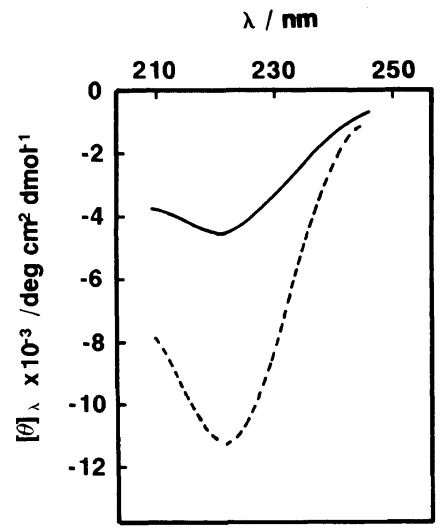

Figure 2. $\mathrm{CD}$ spectra of a membrane composed of $\operatorname{rose}(\mathrm{CN})-\mathrm{PGA}$ at $25^{\circ} \mathrm{C}$ :----, in the dark; - - , on UV irradiation.

associated with the $\alpha$-helix content, was observed. The helix content was calculated by a similar method ${ }^{18}$ of Fasman et al. The helix content of rose(CN)-PGA membrane at $\mathrm{pH}$ 5.3 in the dark was estimated to be $38 \%$ from the value of the molar ellipticity at $222 \mathrm{~nm}$, $[\theta]_{222}$. It is also clear that the light irradiation could decrease the negative value of $[\theta]_{222}$ from $-1.07 \times 10^{4}$ to $-4.40 \times 10^{3} \mathrm{deg} \mathrm{cm}^{2} \mathrm{dmol}^{-1}$, indicating the further photoinduced destabilization of the $\alpha$-helix structure of $\operatorname{rose}(\mathrm{CN})$ PGA membrane. We have also reported the photoinduced conformational change of the polypeptide membrane composed of rose$(\mathrm{OH})-$ PGA. ${ }^{15}$ The light irradiation on the rose-PGA membrane could induce changes in the backbone structure of the polypeptide in the membrane. This behavior can be explained in terms of the cooperative effect between the photodissociation of the pararosaniline leucohydroxide moiety with production of a hydroxide ion and induced acid dissociation of L-glutamic acid moiety accompanied by increase in $\mathrm{pH}$ in the membrane phase on the irradiation. In the present $\operatorname{rose}(\mathrm{CN})-\mathrm{PGA}$ membrane system, however, the degree of dissociation of L-glutamic acid moiety is considered to be insensitive to the light irradiation, since the photodissociation of the light 


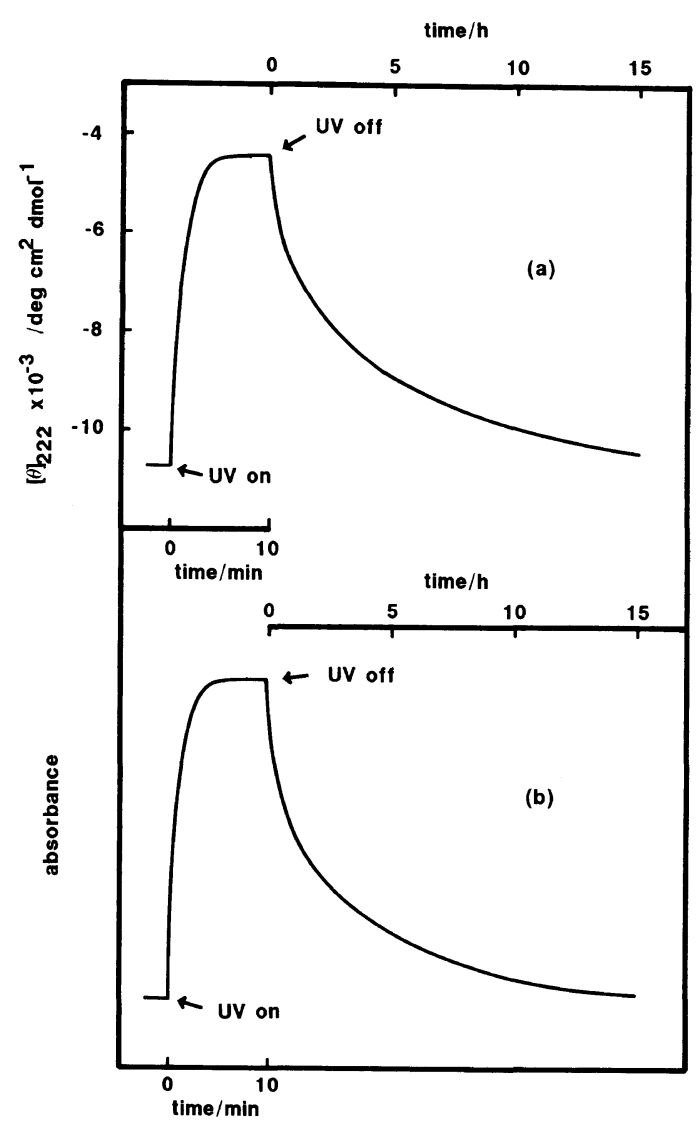

Figure 3. (a) Changes in the molar ellipticity at $222 \mathrm{~nm},[\theta]_{222}$, of a membrane composed of $\operatorname{rose}(\mathrm{CN})-$ PGA on UV irradiation and dark adaptation at $25^{\circ} \mathrm{C}$.

(b) Changes in the absorbance at $576 \mathrm{~nm}$ of the same membrane as (a) on UV irradiation and dark adaptation at $25^{\circ} \mathrm{C}$.

accepting group in the membrane, the rose $(\mathrm{CN})$ moiety, did not induce any changes in $\mathrm{pH}$ in the membrane phase. On the other hand, as is noted above, the $\operatorname{rose}(\mathrm{CN})$ moiety itself could be dissociated into the triarylmethyl cation by the irradiation at $\mathrm{pH}$ 5.3. The photoinduced $\alpha$-helix destabilization of the rose $(\mathrm{CN}$ )-PGA membrane at $\mathrm{pH} 5.3$ (Figure 2), therefore, can be simply attributed to the photoinduced increase of the electrostatic repulsion among the side chain triarylmethyl cations produced by the light irradiation. ${ }^{19}$ It was also shown that, after removal of the light, the $[\theta]_{222}$ value returned to the original value for $15 \mathrm{~h}$ at $25^{\circ} \mathrm{C}$ (Figure 3(a)). This photoinduced conformational transition was almost consistent with the changes in the absorbance at $576 \mathrm{~nm}$ in Figure 3(b)).

\section{Photoinduced Membrane Potential Change of} the Rose $(C N)-P G A$ Membrane

Figure 4 shows the $\mathrm{KCl}$-concentration dependence of the membrane potential, $\Delta(\Delta \phi)$, of the dark-adapted and irradiated $\operatorname{rose}(\mathrm{CN})-$ PGA membrane with a $\mathrm{KCl}$ concentration gradient across the membrane of $c_{1} / c_{2}=10$ at $25^{\circ} \mathrm{C}$. The light irradiation was carried out at $\mathrm{pH}$ 5.3. The value of the dark-adapted membrane potential indicates that the fixed charges in the membrane are positive even in the dark. This would be attributable to the protonated amino $\left(-\mathrm{NH}_{3}{ }^{+}\right)$groups in the rose $(\mathrm{CN})$ moieties of rose $(\mathrm{CN})-\mathrm{PGA}$ membrane at this $\mathrm{pH}$. It was found that light irradiation shifted the membrane potentials to higher values in a wide range of $\mathrm{KCl}$ concentration. As a result, the membrane potential under the irradiation in the low concentration region was almost equal to the ideal Nernst Potential, which is $59 \mathrm{mV}$ with $c_{1} / c_{2}=10$. The membrane potential is represented as the sum of diffusion potential, associated with the mobility of small ions in the membrane, and Donnan potential and generally given as ${ }^{20}$

\section{$\Delta(\Delta \phi)$}

$$
\begin{gathered}
=-\frac{R T}{F}\left[\ln \frac{c_{2}}{c_{1}}+\ln \left\{\frac{\sqrt{1+\left(\frac{2 K_{ \pm} c_{1}}{\phi X}\right)^{2}}+1}{\sqrt{1+\left(\frac{2 K_{ \pm} c_{2}}{\phi X}\right)^{2}}+1}\right\}\right. \\
+\left(\frac{\bar{l}_{+}-\bar{l}_{-}}{\bar{l}_{+}+\bar{l}_{-}}\right) \ln \left\{\frac{\sqrt{1+\left(\frac{2 K_{ \pm} c_{2}}{\phi X}\right)^{2}}+\frac{\bar{l}_{+}-\bar{l}_{-}}{\bar{l}_{+}+\bar{l}_{-}}}{\sqrt{1+\left(\frac{2 K_{ \pm} c_{1}}{\phi X}\right)^{2}}+\frac{\bar{l}_{+}-\bar{l}_{-}}{\bar{l}_{+}+\bar{l}_{-}}}\right\}
\end{gathered}
$$

where $\bar{l}_{+}$and $\bar{l}_{-}$are the mobilities of $\mathrm{K}^{+}$and 


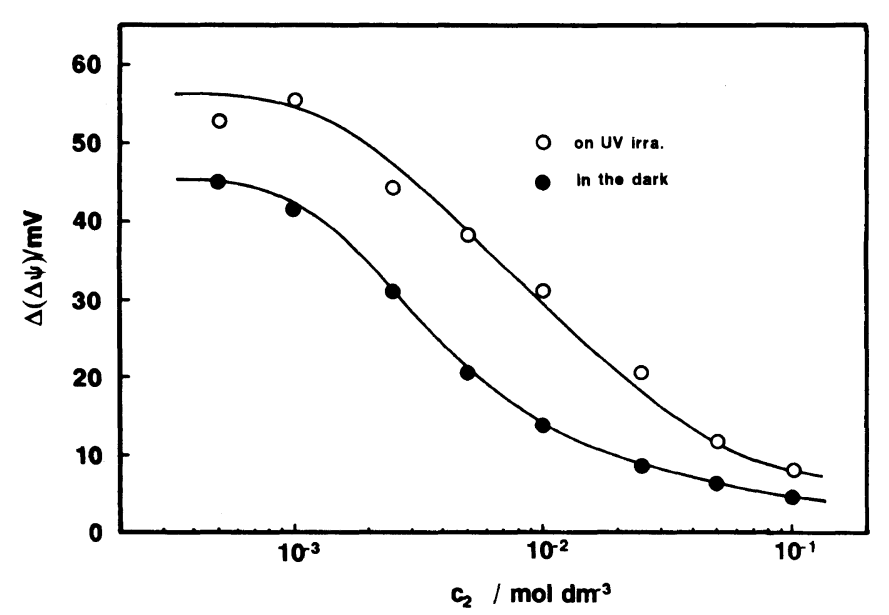

Figure 4. Concentration dependence of membrane potentials of a membrane composed of rose $(\mathrm{CN})-$ PGA at $25^{\circ} \mathrm{C}$ : $\bigcirc$, in the dark; $\bigcirc$, on UV irradiation.

Table I. Effects of UV irradiation on the charge density, $\phi X / K_{ \pm}$, and transport numbers of $\mathrm{K}^{+}$and $\mathrm{Cl}^{-}\left(t_{+}\right.$and $t_{-}$, respectively) in a membrane composed of $\operatorname{rose}(\mathrm{CN})-\mathrm{PGA}$ at $25^{\circ} \mathrm{C}$

\begin{tabular}{ccc}
\hline & In the dark & On UV irradiation \\
\hline$\phi X / K_{ \pm}\left(\mathrm{moll}^{-1}\right)$ & $1.20 \times 10^{-2}$ & $3.89 \times 10^{-2}$ \\
$t_{+}$ & 0.528 & 0.528 \\
$t_{-}$ & 0.472 & 0.472 \\
\hline
\end{tabular}

$\mathrm{Cl}^{-}$ions, respectively, in the membrane, $\phi X$ is the effective charge density of the membrane, $K_{ \pm}$is the equilibrium partition coefficient, and $R, T, F$ are commonly used notations. Applying eq 3 to the experimental data in the high concentration region in Figure 4 where the value of $\phi X$ is assumed to be independent of the concentration, we can estimate the photoinduced changes in the charge density of the membrane, $\phi X / K_{ \pm}$, and transport numbers of $\mathrm{K}^{+}$and $\mathrm{Cl}^{-}$in the membrane, $t_{+}=\bar{l}_{+} /$ $\left(\bar{l}_{+}+\bar{l}_{-}\right)$and $t_{-}=\bar{l}_{-} /\left(\bar{l}_{+}+\bar{l}_{-}\right)$, respectively. The results are shown in Table I. It was found that irradiation additively increased the positive fixed charges in the membrane, whereas the transport numbers were almost insensitive to the irradiation. The photoinduced increase in the membrane potential, therefore, is at-

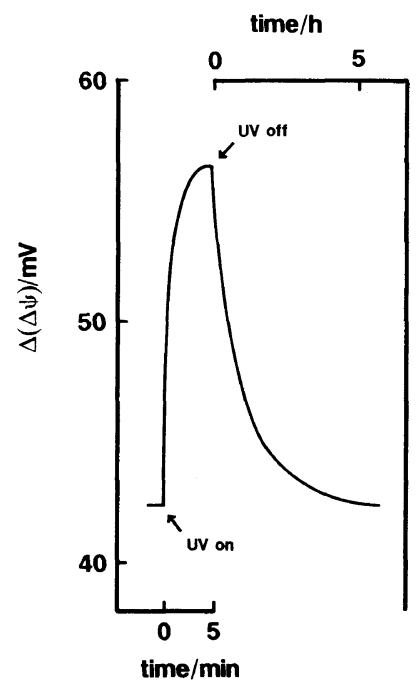

Figure 5. Changes in membrane potential of a membrane composed of rose $(\mathrm{CN})-\mathrm{PGA}$ at $c_{1}=1.0 \times 10^{-2}$ mol dm ${ }^{-3}$ and $c_{2}=1.0 \times 10^{-3} \mathrm{moldm}^{-3}$ on UV irradiation and dark adaptation at $25^{\circ} \mathrm{C}$.

tributable to the changes in the Donnan potential at membrane-solution interfaces resulting from the photodissociation of the $\operatorname{rose}(\mathrm{CN})$ moieties into cationic side chains. Figure 5 shows the changes in the membrane potentials of rose $(\mathrm{CN})-\mathrm{PGA}$ membrane with $c_{1}=1.0 \times$ $10^{-2}$ and $c_{2}=1.0 \times 10^{-3} \mathrm{moldm}^{-3}$ at $\mathrm{pH} 5.3$ and at $25^{\circ} \mathrm{C}$. It is clear that the membrane po- 
tential, i.e., the fixed charge density of rose(CN)-PGA membrane, can be reversibly regulated by the light irradiation.

\section{Photoinduced Permeability Change of the Rose $(C N)-P G A$ Membrane}

Figure 6 shows the permeation curve of $\mathrm{KCl}$ through the rose(CN)-PGA membrane when the $\mathrm{KCl}$ concentration of the feed side of the membrane is $1.0 \mathrm{~mol} \mathrm{dm}^{-3}$ at $\mathrm{pH} 5.3$. It is seen that the permeation amount of $\mathrm{KCl}$ increased linearly with time in the dark. Moreover, when the membrane was irradiated, the permeation of the solute immediately increased. The permeation coefficient, $P_{\mathrm{s}}$, was obtained from the slope of the permeation curve in Figure 6 and eq 2 keeping the thickness of $\operatorname{rose}(\mathrm{CN})$ PGA membrane, $17 \mu \mathrm{m}$ in the dark, constant. The result is shown as a function of time in Figure 7(a). The value of $P_{\mathrm{s}}$ increased from $3.51 \times 10^{-7} \mathrm{~cm}^{2} \mathrm{~s}^{-1}$ to $5.56 \times 10^{-6} \mathrm{~cm}^{2} \mathrm{~s}^{-1}$, by a factor of 16 , by the light irradiation. Furthermore, in order to estimate a more accurate increase in the permeability coefficient associated with light irradiation, it is necessary to take into account the photoinduced changes in the membrane thickness. The thickness of rose $(\mathrm{CN})-\mathrm{PGA}$ membrane increased from $17 \mu \mathrm{m}$ to $24 \mu \mathrm{m}$ by light irradiation. As a result, the value of $P_{2}$ under the light irradiation at $\mathrm{pH} 5.3$ was modified to be $7.84 \times 10^{-6} \mathrm{~cm}^{2} \mathrm{~s}^{-1}$ by applying the photoinduce swollen membrane thickness, $24 \mu \mathrm{m}$, to eq 2 . It has become apparent, therefore, that the value of $P_{\mathrm{s}}$ increases essentially by a factor of 22 .

Figure 7(b) shows, on the other hand, the changes in the degree of hydration of the rose $(\mathrm{CN})-\mathrm{PGA}$ membrane on light irradiation. The light irradiation of $\operatorname{rose}(\mathrm{CN})$ PGA membrane produced cationic side chains and increased the content of hydrophilic backbone, random coil, in the membrane, both of which, in turn, caused increased in the polarity of the membrane. In addition, it has been shown that the increase in the osmotic pressure

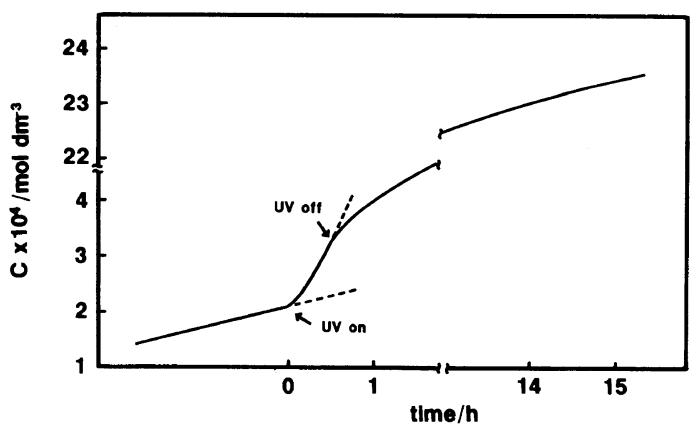

Figure 6. Changes in the permeability of $\mathrm{KCl}$ across a membrane composed of rose $(\mathrm{CN})-\mathrm{PGA}$ on UV irradiation and dark adaptation at $25^{\circ} \mathrm{C}$.

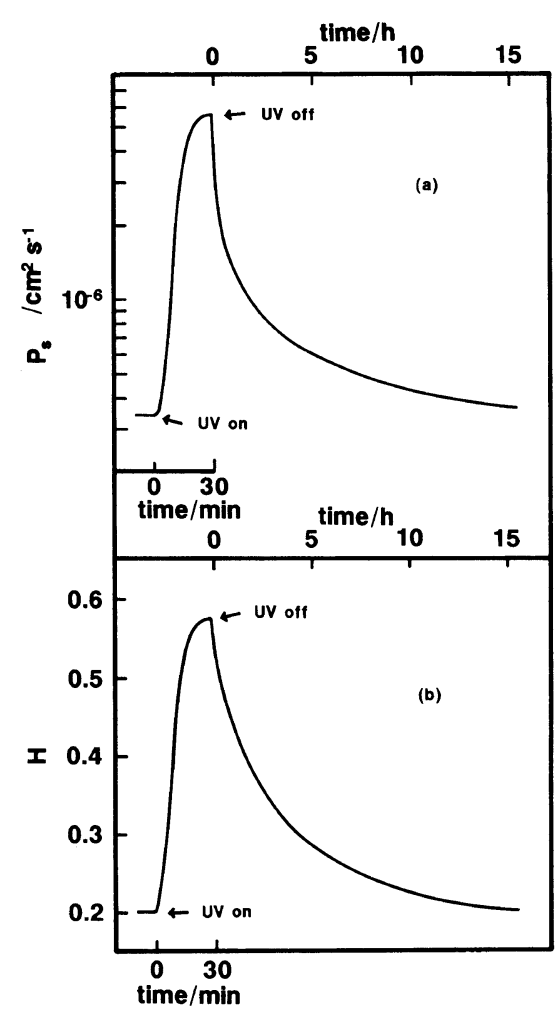

Figure 7. (a) Changes in the permeability coefficient of $\mathrm{KCl}, \mathrm{Ps}$, across a membrane composed of $\operatorname{rose}(\mathrm{CN})-$ PGA on UV irradiation and dark adaptation at $25^{\circ} \mathrm{C}$. (b) Changes in the degree of hydration, $\mathrm{H}$, of the same membrane as (a) on UV irradiation and dark adaptation at $25^{\circ} \mathrm{C}$.

between membrane and aqueous phase, resulting in membrane swelling, was induced by light irradiation owing to the photoproduction 
of $\mathrm{CN}^{-}$ions in the membrane phase. ${ }^{17}$ As is expected, the degree of hydration of the membrane increased by irradiation and returned to its original value in the dark. Thus, possibly, one of the main factor for increasing the permeability through $\operatorname{rose}(\mathrm{CN})-\mathrm{PGA}$ membrane is the increase in the free volume of the membrane via the photoinduced membrane swelling. It is also clear from Figure 7 that photoinduced permeability change (Figure 7(a)) is entirely consistent with the change in the degree of hydration of the membrane (Figure 7(b)) and also with the conformational response to light in Figure 2. Therefore, it is concluded that the enormous increase of the rose $(\mathrm{CN})-\mathrm{PGA}$ membrane permeability by UV irradiation can be attributed to the effective increase in the degree of hydration of the membrane resulting from conformational change of rose(CN)-PGA and changes in osmotic pressure by UV irradiation.

Acknowledgement. The authors gratefully acknowledge the support of the Japanese Ministry of Education through Grant-in-Aid for Developmental Science Research.

\section{REFERENCES}

1. L. Lamarre and C. S. P. Sung, Macromolecules, 16, 1729 (1983).
2. M. Irie and W. Schnabel, Macromolecules, 14, 1246 (1981).

3. A. Ueno, K. Takahashi, J. Anzai, and T. Osa, J. Am. Chem. Soc., 103, 6410 (1981).

4. F. Ciardelli, O. Pieroni, A. Fissi, and J. L. Houben, Biopolymers, 23, 1423 (1984).

5. M. Irie, Y. Hirano, S. Hashimoto, and K. Hayashi, Macromolecules, 14, 263 (1981).

6. A. Menju, K. Hayashi, and M. Irie, Macromolecules, 14, 755 (1981).

7. G. S. Kumar, P. DePra, and D. C. Neckers, Macromolecules, 17, 1912 (1984).

8. T. Kinoshita, A. Takizawa, and Y. Tsujita, Nippon Kagaku Kaishi, 868 (1983).

9. A. Takizawa, T. Kinoshita, A. Ohtani, and Y. Tsujita, J. Polym. Sci., Polym. Chem. Ed., 24, 665 (1986).

10. M. Sato, T. Kinoshita, A. Takizawa, and Y. Tsujita, Macromolecules, 21, 1612 (1988).

11. T. Kinoshita, M. Sato, A. Takizawa, and Y. Tsujita, J. Am. Chem. Soc., 108, 6399 (1986).

12. J. G. Calvert and H. J. L. Rechen, J. Phys. Chem., 2101 (1952).

13. M. Sato, T. Kinoshita, A. Takizawa, Y. Tsujita, and R. Ito, Polym. J., 20, 761 (1988).

14. M. L. Herz, J. Am. Chem. Soc., 97, 6777 (1975).

15. M. Sato, T. Kinoshita, A. Takizawa, and Y. Tsujita, Macromolecules, in press.

16. H. Sasaki, A. Ueno, and T. Osa, Bull. Chem. Soc. Jpn., 61, 2321 (1988).

17. M. Irie and D. Kunwatchakun, Macromolecules, 19, 2476 (1986).

18. N. Greenfield and G. D. Fasman, Biochemistry, 8, 4108 (1969).

19. M. Irie and M. Hosoda, Makromol. Chem., Rapid Commun., 6, 533 (1985).

20. A. Takizawa, Hyomen, 20, 68 (1982). 